\title{
Editorial
}

\section{La ingenieria y las ciencias naturales}

El Diccionario de la Real Academia de la lengua española define Ingeniería como el "estudio y aplicación, por especialistas, de las diversas ramas de la tecnología" y Ciencia, como el "conjunto de conocimientos obtenidos mediante la observación y el razonamiento, sistemáticamente estructurados y de los que se deducen principios y leyes generales"; las Ciencias naturales son "las que tienen por objeto el estudio de la naturaleza, como la geología, la botánica, la zoología. A veces se incluyen la fisica, la
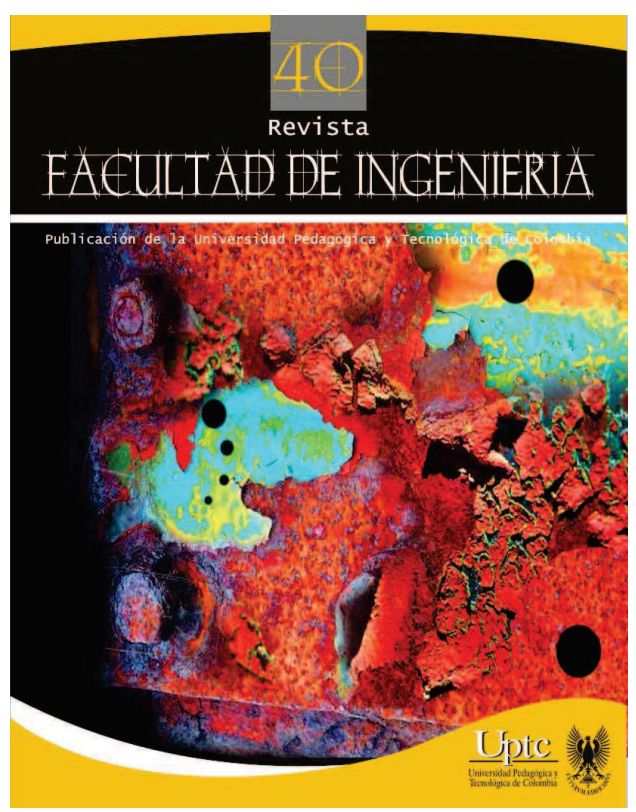

La imagen se compone de tres distintas fotografías en las que elevando su saturación se emula las imágenes termográficas mencionadas en uno de los artículos, así como elementos víctimas del desgaste por abrasión. La imagen, cortada abruptamente a la izquierda hacia el negro del fondo refuerza esta idea.

La Ley 842, promulgada por el Congreso de la República de Colombia en 2003, señala: "se entiende por ingeniería toda aplicación de las ciencias fisicas, químicas y matemáticas; de la técnica industrial y en general, del ingenio humano, a la utilización e invención sobre la materia".

La Organización para la Cooperación y el Desarrollo Económicos (OCDE), considera seis grandes áreas científicas: las Ciencias Naturales; la Ingeniería y Tecnología; y otras cuatro. Con relación a la Ingeniería y Tecnología relaciona 11 áreas, las Ingenierías: Civil; Eléctrica, Electrónica e Informática; Mecánica; Química; de los Materiales; Médica; y Ambiental; las Biotecnologías: Ambiental; e Industrial; la Nanotecnología; y Otras Ingenierías y Tecnologías; registra en total 46 disciplinas. Respecto a las Ciencias Naturales se referencian seis áreas: Matemática; Computación y ciencias de la información; Ciencias físicas; Ciencias químicas; Ciencias de la tierra y medioambientales; y Ciencias biológicas; con 42 disciplinas.

Los programas académicos de Ingeniería consideran disciplinas de las Ciencias Naturales, de las indicadas por la OCDE; por ejemplo, en la formación básica: Matemáticas; Estadística y probabilidades; Química física; Química inorgánica y nuclear; Ciencias de la com- 
putación; entre otras; $\mathrm{y}$ en la formación específica, según el programa académico: Óptica; Acústica; Ciencias de los polímeros; Electroquímica; Química orgánica; Química de los coloides; Química analítica; Geociencias; Mineralogía; Geología, Ciencias del medio ambiente; por señalar algunas de ellas.

El Ministerio de Educación Nacional de Colombia, considera ocho áreas del conocimiento: Ingeniería, Arquitectura, Urbanismo y afines; Matemáticas y Ciencias Naturales; y seis más; cada área comprende núcleos básicos de conocimiento, que para el caso de la Ingeniería son 16: Arquitectura; Ingenierías: Administrativa y afines; Agrícola, Forestal y afines; Agroindustrial, Alimentos y afines; Agronómica, Pecuaria y afines; Ambiental, Sanitaria y afines; Biomédica y afines; Civil y afines; de Minas, Metalúrgica y afines; de Sistemas, Telemática y afines; Eléctrica y afines; Electrónica, Telecomunicaciones y afines; Industrial y afines; Mecánica y afines; Química y afines; Otras. Con relación a Matemáticas y Ciencias Naturales se consideran los siguientes cinco núcleos básicos de conocimientos: Biología, Microbiología y afines; Física; Geología, otros programas de ciencias naturales; Matemáticas, Estadística y afines; y Química y afines.

En los planes de estudio de diversos programas de Ingeniería las Matemáticas y Ciencias naturales conforman un porcentaje significativo de los créditos académicos que debe aprobar el futuro profesional, por ejemplo, en la Facultad de Ingeniería de la Universidad Pedagógica y Tecnológica de Colombia (planes de estudio ajustados en 2009), Electrónica contiene el 49\%, Civil el 55\%, Sistemas y Computación el 49\%, Metalurgia el 56\%, Transporte y Vías el 51\%, Ambiental el 60\%, considerando dentro de las Matemáticas y Ciencias naturales asignaturas como: Cálculo, Física, Química, Biología, Geología, Álgebra lineal, Probabilidad y Estadística, según el programa académico.

La formación de los ingenieros se soporta en diversas disciplinas, entre ellas, de manera relevante, las de Matemáticas y Ciencias naturales, por lo cual, en instituciones de educación superior que ofrezcan programas académicos en Matemáticas y Ciencias naturales, es conveniente apoyarse en sus docentes para formar a los futuros ingenieros, dado su conocimiento profundo en la materia, con la misma rigurosidad en su selección que la considerada al escoger ingenieros especializados para las asignaturas del área específica de la disciplina de la Ingeniería ofrecida; ello constituirá un insumo fundamental con miras a ofrecer a la sociedad un Ingeniero con mayores potencialidades.

Algunos académicos consideran que los Ingenieros deben ser formados por Ingenieros, descartando la participación de otros profesionales, aún a sabiendas que el ingeniero debe formarse integralmente y tener una importante fundamentación en las Matemáticas y Ciencias naturales; se busca apoyo al planteamiento en la sesgada interpretación de lo señalado por la Ley 842 de 2002 en el parágrafo de su Artículo 2, que menciona: "La instrucción, formación, enseñanza, docencia o cátedra dirigida a los estudiantes que aspiren a uno de los títulos profesionales, afines o auxiliares de la Ingeniería, en las materias $o$ asignaturas que impliquen el conocimiento de la profesión, como máxima actividad del ejercicio profesional, solo podrá ser impartida por profesionales de la ingeniería, sus profesiones afines o sus profesiones auxiliares, según el caso, debidamente matriculados."

Del aparte antes citado se olvida frecuentemente la aclaración que allí mismo se indica sobre la participación del ingeniero como formador: "en las materias o asignaturas que impliquen el conocimiento de la profesión", que al no considerarla, desprecia la sinergia que se logra al dar participación a las Matemáticas y Ciencias naturales en la formación del Ingeniero, como explícitamente lo indica el enunciado de la misma norma, en su artículo primero, en el cual se plasma el "concepto de ingeniería" y donde se hace énfasis en la importancia de la aplicación de las Ciencias, para desarrollar las actividades de la Ingeniería

Dada la importante participación de las Matemáticas y Ciencias naturales en la formación del ingeniero, con el objeto de dotarlo de conocimientos para su uso en la mejora de productos, el progreso del entorno y la solución de los problemas que debe afrontar, puede considerarse que las Matemáticas y Ciencias naturales se constituyen en un medio requerido para la innovación y el desarrollo, afines a la ingeniería, que llevan a considerarla como Ciencia aplicada.

Ph. D. Daniel Humberto Cárdenas-Guevara Decano Facultad de Ingeniería Universidad Pedagógica y Tecnológica de Colombia 